\title{
A Systematic Review and Meta-Analysis on the Epidemiology of Hepatitis B and Hepatitis C Virus among Beta-Thalassemia Major Patients in Pakistan
}

\author{
Usman Waheed ${ }^{1,2} \quad$ Noore Saba ${ }^{3}$ Akhlaaq Wazeer ${ }^{4,5}$ \\ ${ }^{1}$ Department of Pathology and Transfusion Medicine, Shaheed \\ Zulfiqar Ali Bhutto Medical University, Islamabad, Pakistan \\ Islamabad Blood Transfusion Authority, Ministry of National Health \\ Services, Islamabad, Pakistan \\ ${ }^{3}$ Peshawar Regional Blood Centre, Department of Health, Peshawar, \\ Pakistan \\ ${ }^{4}$ Department of Biotechnology, Mirpur University of Science and \\ Technology, Mirpur, Azad Jammu and Kashmir, Pakistan \\ ${ }^{5}$ Department of Pathology and Transfusion Medicine, Divisional \\ Headquarters Teaching Hospital, Mirpur, Azad Jammu and \\ Kashmir, Pakistan \\ ${ }^{6}$ Department of Blood Bank, Prince Mohammed bin Abdulaziz \\ Hospital, Riyadh, Saudi Arabia
}

Saeed Ahmed ${ }^{6}$

J Lab Physicians 2021;13:270-276.

\author{
Address for Correspondence Usman Waheed, PhD, Islamabad \\ Blood Transfusion Authority, Ministry of National Health Services, \\ Islamabad 44000, Pakistan \\ (e-mail: drusman.waheed1@gmail.com).
}

\begin{abstract}
Keywords

- thalassemia

- hepatitis B

- hepatitis C

- epidemiology

- Pakistan

Beta-thalassemia major patients are the leading consumers of blood transfusions in Pakistan and, therefore, have a greater risk of acquiring transfusion-transmitted infections, most notably hepatitis B and C virus (HBV and HCV). The present study includes a comprehensive review on the status of HBV and HCV in beta-thalassemia major patients in Pakistan. For this purpose, we examined original articles assessing the epidemiology of HBV and HCV in transfusion-dependent thalassemia patients.

We searched 10 major subscription databases from January through February 2020, that is, Medline, PakMediNet, CINAHL, Scopus, PubMed, Web of Science, Embase, Science Direct, Google Scholar, and Directory of Open Access Journals. The World Health Organization resources were also explored for relevant reports. The search criteria included published articles up to December 31, 2019, with no language restrictions. Articles identified were introduced into the Endnote version X9 software and then screened for relevance and duplication. The results were stated as the pooled prevalence for the overall study and also for region-wise subgroups.

A total of 33 studies conducted from 1995 to 2019 were included in the review. All 33 articles yielded information on HCV prevalence, while 19 of them provided information on HBV prevalence. The overall sample size was 8,554 that tested the prevalence of HCV in thalassemia patients. The sample size from the 19 studies that tested the prevalence of HBV was 6,184 . The overall pooled prevalence of HBV was computed to be $4.13 \%$, while the pooled prevalence of HCV was $29.79 \%$. The majority of the studies were obtained from the Punjab Province (33.33\%), followed by Khyber Pakhtunkhwa Province (24.24\%).
\end{abstract}

published online June 28, 2021
DOI https://doi.org/

$10.1055 / \mathrm{s}-0041-1731110$ ISSN 0974-2727
C 2021. The Indian Association of Laboratory Physicians.

This is an open access article published by Thieme under the terms of the Creative Commons Attribution-NonDerivative-NonCommercial-License, permitting copying and reproduction so long as the original work is given appropriate credit. Contents may not be used for commercial purposes, or adapted, remixed, transformed or built upon. (https://creativecommons.org/licenses/by-nc-nd/4.0/).

Thieme Medical and Scientific Publishers Pvt. Ltd. A-12, 2nd Floor, Sector 2, Noida-201301 UP, India 
The total sample size of 33 studies was less than $10 \%$ of the total number of estimated thalassemic patients, that is, 100,000 . Further studies or a national baseline survey are imperative to confirm the actual frequency of HBV and HCV in thalassemia patients across the country.

\section{Introduction}

Beta-thalassemia is a monogene hereditary blood disorder resulting due to alteration of globin chain synthesis, characterized by reduced hemoglobin in erythrocytes and anemia. ${ }^{1}$ The disease is predominantly present in regions where malaria incidence is high as thalassemic erythrocytes are responsible for immunity against the organism. ${ }^{2}$ A high frequency of thalassemia carriers is seen in the Middle East, the Indian subcontinent, Southeast Asia, and South China. Cyprus (14\%) has the highest carrier rate followed by Sardinia $(10.3 \%){ }^{3}$ In the past few decades, migration of population and intermarriages among various ethnic groups have led thalassemia to almost every country around the globe.

Beta-thalassemia in its homozygous state (i.e., thalassemia major) is characterized by profound anemia and death before the age of 3 years. ${ }^{4}$ However, the life expectancy of thalassemic patients has increased because of the availability of regular blood transfusion and iron chelation therapy. ${ }^{5}$ The objective of the blood transfusion regimen in beta-thalassemia major is to treat anemia that prevents stunted growth, organ damage, and bone deformities, increasing the quality of life. ${ }^{6}$ However, this therapy has its side effects and results in several complications namely iron overload, ${ }^{7}$ alloimmunization, ${ }^{8}$ adverse transfusion reactions, ${ }^{9}$ and the transmission of transfusion-transmitted infections (TTIs) mostly notably hepatitis B and hepatitis C virus (HBV and HCV). ${ }^{10,11}$

First reported in $1960,{ }^{12}$ thalassemia is the most frequent genetic disorder seen in the country ${ }^{13}$ and a major health care challenge for Pakistan. ${ }^{14}$ About $5 \%{ }^{15}$ of the population is heterozygous for beta-globin gene (thalassemia minor) and the number of patients with thalassemia major is estimated to be $100,000 .{ }^{16}$ However, as no baseline survey has ever been conducted, the exact burden of the disease is unknown. ${ }^{16}$ Thalassemia incidence is seeing an upward trend despite being a preventable disease, attributed mainly to the absence of a national strategy. As a result, there are no national prevention, control, or management plans.

Thalassemia individuals are the leading consumers of blood transfusions in the country. These patients are not hospitalized yet require regular transfusions placing an enormous burden on the families as well as on the fragmented demand-driven ${ }^{17}$ blood transfusion system in the country. It is pertinent to mention that two of the provinces (Sindh ${ }^{18}$ and Balochistan ${ }^{19}$ ) have enacted legislation to prevent and control thalassemia in their respective jurisdictions. However, due to weak regulatory oversight and implementation mechanisms, they have not been enacted in earnest.
There are limited facilities for thalassemia patients in the government hospitals and thalassemic patients were the primary reason for the proliferation of nongovernmental organization (NGO) sector thalassemia centers in the country. ${ }^{20}$ These patients are mostly treated by these NGOs whose standard of services varies. Some of these centers are not adequately equipped, have poor technical expertise, and place major emphasis on getting the blood transfusions neglecting other interventions including quality-assured screening for TTIs, among others. Many studies have reported a high incidence of TTIs in transfusion-dependent thalassemia patients. However, there is significant variation present in the individually published articles with regard to the number of patients tested, the number of positive patients, and the type of screening technique. Therefore, it is challenging to estimate the current pooled prevalence from those individual studies.

In addition, the reduction of hepatitis burden in the country is high on the Pakistan government's agenda. The government formulated and implemented a national hepatitis strategic framework (2017-2021). ${ }^{21}$ Hence, estimating the latest figures regarding $\mathrm{HBV}$ and $\mathrm{HCV}$ pooled prevalence in thalassemia cohort is necessary to understand prevalence dynamics and risk factors to formulate targeted and cost-effective preventative and treatment interventions to attain the target of hepatitis elimination.

We conducted this study with the objective to summarize and assess the epidemiology of HBV and HCV among thalassemic patients by performing a comprehensive systematic review and meta-analysis of relevant published studies from Pakistan.

\section{Methodology}

We searched the PROSPERO database and database of abstracts of reviews of effects (http://www.library.UCSF.edu) to see if the published or ongoing projects are present related to our topic. The methodological framework articulated by the Cochrane Collaboration Handbook ${ }^{22}$ was used to guide the current study. The study was based on the PRISMA (Preferred Reporting Items for Systematic Reviews and Meta-Analyses) 2009 guidelines. ${ }^{23}$ The detailed methodology of the study is briefed in the succeeding sections.

\section{Data Sources and Article Identification}

We searched 10 major subscription databases from January through February 2020, that is, Medline, PakMediNet, CINAHL, Scopus, PubMed, Web of Science, Embase, Science Direct, Google Scholar, and Directory of Open Access Journals. The World Health Organization (WHO) resources were also 
explored for relevant reports. Medical subject heading terms with free text words were utilized in research equations with Boolean operators (AND, OR, and NOT). The keywords employed to search the mentioned databases included hepatitis $C$, hepatitis $B$, hepatitis B surface antigen, virus hepatitis, epidemiology, prevalence, seroprevalence, thalassemia major, transfusion-transmitted, Pakistan, as well as variations thereof. The search criteria included published articles up to December 31, 2019, with no language restrictions.

\section{Article Selection and Eligibility Criteria}

All articles identified through our above-mentioned databases were introduced into the Endnote version X9 software (reference manager), where duplicate publications were recognized and excluded independently by two of the authors (UW, NS). The remaining articles underwent a two-stage screening process, to determine eligibility and relevancy. This included the title and abstract screening, followed by a fulltext review using our inclusion and exclusion criteria. Eligible articles were included and others excluded. Identification of additional articles was made through screening of references in full-text articles (i.e., handcomb search) as well as the gray literature, for example, country- or province-level reports. After the identification of articles that met inclusion criteria, two authors (UW, AW) independently reviewed all full-text articles. When agreement on inclusion was not reached between the two reviewers, a third reviewer arbitrated to reach a consensus.

The inclusion criteria used in the current study were any article with full-text reporting HBV or HCV prevalence in thalassemia major patients in Pakistan based on primary data. Review articles were not included but all data present in them were checked and matched to the present search results. Any additional study identified in reviews and not retrieved by the present search was included. All other articles were excluded such as case report, editorial, correspondence, commentary, original articles whose full texts are not retrievable or include study population outside Pakistan, unclear prevalence, or methodological errors.

\section{Data Extraction and Screening}

Each study was allotted a number for identification. The following data (based on ad hoc Excel spreadsheet) were later extracted from every article in the following domains: reference details (this included surname of author, title, journal, year of publication), city and province, study population, sample size, number of thalassemia patients screened for HBV and HCV (in case different from the sample size), number of thalassemia patients who tested positive, screening technique used, and the reported prevalence and incidence of HBV and HCV. Any discrepancy regarding the extracted data was resolved by discussion and mutual consensus.

\section{Article Quality Appraisal}

Two authors independently judged the quality of the included articles using the Joanna Briggs Institute quality assessment tool for prevalence and epidemiological studies ${ }^{24}$ with 10 questions. The answer to each question was yes, no, not clear, or not applicable. The quality of each included article was scored as poor (below the mean score) and good (mean score and above).

\section{Data Analyses}

To summarize the characteristics of included studies, numeric analysis was applied. The result was reported as pooled prevalence for the overall study and also for region-wise subgroups.

\section{Results}

\section{Literature Search}

-Fig. 1 shows the steps for the selection of studies into this systematic review after adapting the PRISMA flow diagram. Briefly, a total of 94 citations were obtained using the search strategy for the identified databases. After the removal of 20 duplicate articles, the remaining 74 articles underwent title and abstract screening. Based on title and abstract scan, 46 articles were excluded not fulfilling the inclusion criteria and 28 remained for full-text review. One full-text article was further removed due to methodological errors. From the handcomb search, six potentially eligible articles were identified and added to the systematic review. Thus, a total of 33 articles qualified for inclusion in the review. ${ }^{25-57}$ All 33 articles yielded information on HCV prevalence, while 19 of them provided information on HBV prevalence.

\section{Characteristics of Included Studies}

- Table 1 shows the features of studies included in the systematic review. The studies were published from January 1995 to December 2019. Regarding the province-wise coverage, majority of the studies were obtained from Punjab Province 11 (33.33\%), ${ }^{25,34,35,40,42,43,46,48,50,53,55}$ Khyber Pakhtunkhwa Province 8 (24.24\%), 29,32,36,41,44,51,54,57 Sindh Province 6 (18.18\%), ${ }^{26-28,37,39,49}$ Islamabad Capital Territory 3 (9.09\%), 30,45,52 Balochistan Province 1 (3.03\%), ${ }^{38}$ and mixed-province samples $4(12.12 \%)$. $^{31,33,47,56}$ No studies were identified from Azad Jammu and Kashmir and Gilgit-Baltistan regions.

Most of the selected studies performed screening through enzyme-linked immunosorbent assay 23 (69.69\%), while rest through rapid diagnostic test (RDT) devices 4 (12.12\%), chemiluminescence immunoassay 3 (9.09\%), and polymerase chain reaction 3 (9.09\%).

\section{HBV and HCV Epidemiology Overview}

From the 33 studies included in this systematic review, the overall sample size was 8,554 that tested the prevalence of HCV in thalassemia patients. The sample size from the 19 studies that tested the prevalence of HBV was 6,184. The sample size across the studies ranged from $35^{25}$ to $1,440 .{ }^{52}$ The overall pooled prevalence of HBV was computed to be $4.13 \%$, while the pooled prevalence of HCV was $29.79 \%$. There was a wide variation in HBV and HCV prevalence among individual studies. For HBV, it ranged from $0.70 \%$ in Rawalpindi (Punjab Province) ${ }^{34}$ to $8.40 \%$ in Peshawar (Khyber Pakhtunkhwa Province). ${ }^{32}$ For HCV, it ranged from $5.55 \%$ in Hazara (Khyber 


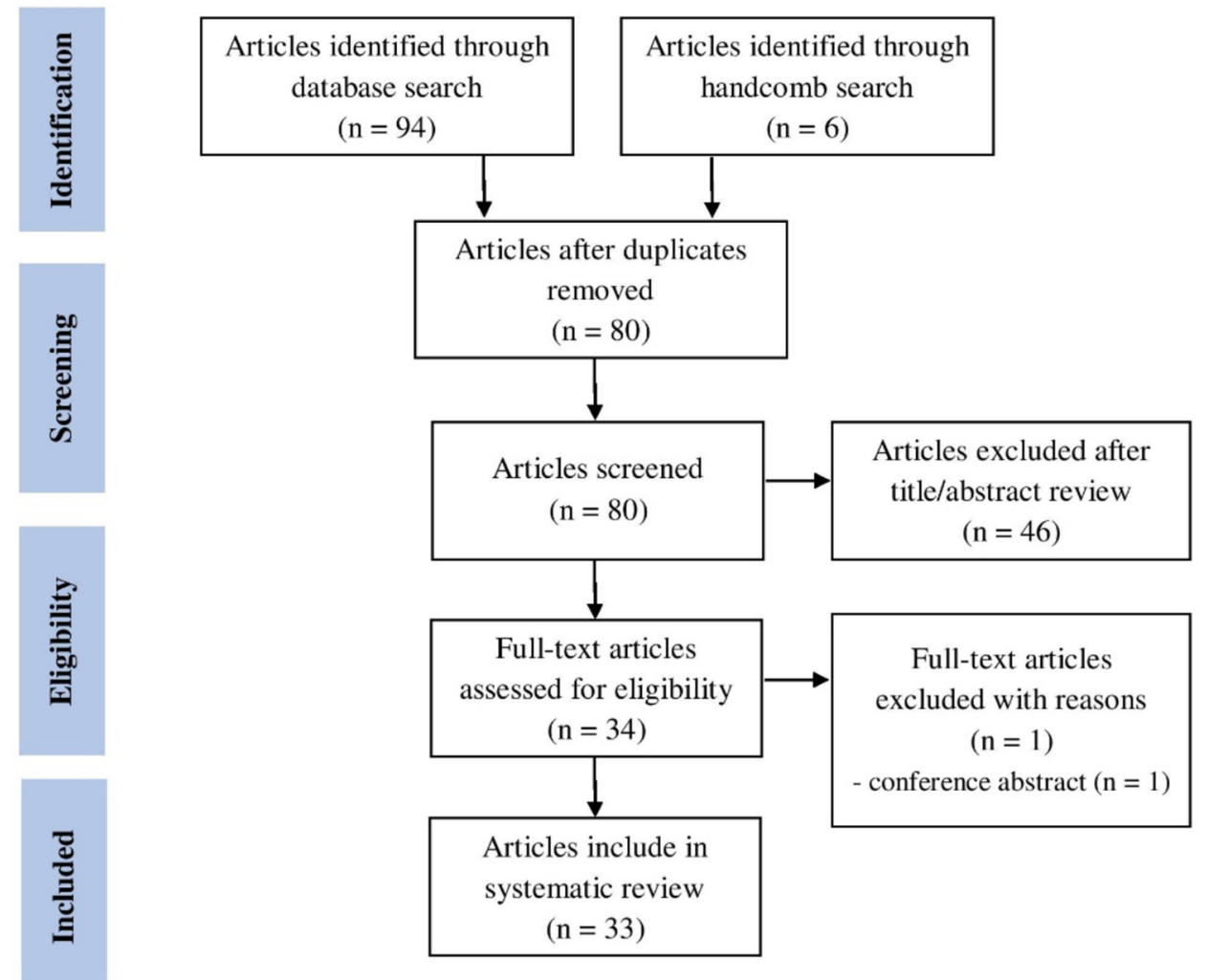

Fig. 1 Flowchart of the process through which articles were selected based on Preferred Reporting Items for Systematic Reviews and Meta-Analyses (PRISMA) 2009 guidelines.

Pakhtunkhwa Province) ${ }^{54}$ to $65 \%$ in Faisalabad (Punjab Province) ${ }^{35}$ Refer to - Table 1 for further details of study characteristics.

\section{HBV and HCV Epidemiology Province-wise}

The pooled subgroup prevalence stratified by geographical location (province) revealed that the prevalence of HCV among beta-thalassemia patients was high $41.34 \%$ in Punjab (based on 11 studies with a sample size of 2,090), compared with $24.17 \%$ of Khyber Pakhtunkhwa (based on 8 studies with a sample size of 1,518), 25.94\% of Sindh (based on 6 studies with a sample size of 1,056$), 26.61 \%$ of Islamabad Capital Territory (based on 3 studies with a sample size of 1,777), and $30 \%$ of Balochistan (based on 1 study with a sample size of 150$)$.

The pooled subgroup prevalence of HBV was high $10.14 \%$ in Punjab (based on 6 studies with a sample size of 483), compared with $5.10 \%$ of Khyber Pakhtunkhwa (based on 5 studies with a sample size of 1,254), 3.80\% of Sindh (based on 4 studies with a sample size of 709), and 3.05\% of Islamabad Capital Territory (based on 2 studies with a sample size of 1,702).

\section{Discussion}

A number of hepatotropic viruses cause viral hepatitis. Among these, HBV and HCV are by far the most important viruses causing both acute and chronic hepatitis. These viruses are still a serious public health concern across the globe, especially among the low-income countries including Pakistan.

The planning to implement appropriate and effective programs to prevent and control these viral syndromes requires the presence and use of scientific evidence that are up-to-date. Therefore, the goal of this review was to determine the pooled prevalence of HBV and HCV among the transfusion-dependent beta-thalassemia major patients, a well-known high-risk group needing regular transfusion to maintain quality of life. We observed highly variable prevalence estimates for both HBV and HCV from different studies in a similar population, even within the same province. The findings of this study indicated that the pooled prevalence of HBV and HCV was 4.13 and $29.79 \%$, respectively. The observed pooled prevalence of HBV and HCV is higher in contrast to prevalence in the general population of the country that stands at 2.5 and $4.9 \%$, respectively. ${ }^{58}$

Safe blood transfusion increases the quality of life and survival of recipients. However, they also expose the recipients to the risk of acquiring TTIs. The probability of acquiring TTIs is linked to the probability of being exposed to the contaminated blood and blood components. This probability is influenced by the prevalence of TTIs in the blood donor population and the number of units being transfused. Thus, the rate of acquiring TTIs increases with age in subsequent years that is the case in chronic recipients of blood such as thalassemia. As the blood collections in Pakistan are predominantly "family 
Table 1 Studies included in the systematic review that assessed the epidemiology of HBV and HCV among Pakistani betathalassemia major patients

\begin{tabular}{|c|c|c|c|c|}
\hline Author and year of publication & City (region) & $\begin{array}{l}\text { Sample } \\
\text { size }\end{array}$ & $\begin{array}{l}\text { HCV positive } \\
(\%)\end{array}$ & HBV positive (\%) \\
\hline Bhatti et al,199525 & Rawalpindi (Punjab) & 35 & $21(60 \%)$ & $2(5.71 \%)$ \\
\hline Abdul Mujeeb et al, $1997^{26}$ & Karachi (Sindh) & 91 & 46 (50.54\%) & NA \\
\hline Shamsi et al, $1998^{27}$ & Karachi (Sindh) & 370 & $60(16.21 \%)$ & $18(4.86 \%)$ \\
\hline Akhtar et al, $2002^{28}$ & Karachi (Sindh) & 256 & $86(33.59 \%)$ & NA \\
\hline Mohammad et al, $2003^{29}$ & Peshawar (KP) & 80 & $29(36.25 \%)$ & $6(7.5 \%)$ \\
\hline Younus et al, $2004^{30}$ & ICT & 75 & $32(42.66 \%)$ & NA \\
\hline Burki et al, $2005^{31}$ & ICT and Peshawar (KP) & 180 & $75(41.66 \%)$ & NA \\
\hline Shah et al, $2005^{32}$ & Peshawar (KP) & 250 & $142(56.80 \%)$ & $21(8.40 \%)$ \\
\hline Hussain et al, $2008^{33}$ & ICT and Peshawar (KP) & 180 & $75(41.66 \%)$ & NA \\
\hline lqbal et al, $2010^{34}$ & Rawalpindi (Punjab) & 141 & $50(35.46 \%)$ & $1(0.70 \%)$ \\
\hline Ain et al, $2011^{35}$ & Faisalabad (Punjab) & 300 & 195 (65\%) & NA \\
\hline Ali et al, $2011^{36}$ & Peshawar (KP) & 40 & $6(15 \%)$ & NA \\
\hline Riaz et al, $2011^{37}$ & Karachi (Sindh) & 79 & $34(43.03 \%)$ & $4(5.06 \%)$ \\
\hline Rehman et al, $2011^{38}$ & Quetta (Balochistan) & 150 & 45 (30\%) & NA \\
\hline Ansari et al, $2012^{39}$ & Karachi (Sindh) & 160 & $21(13.12 \%)$ & $2(1.25 \%)$ \\
\hline Iqbal et al, $2013^{40}$ & Rawalpindi (Punjab) & 95 & $40(42.10 \%)$ & NA \\
\hline Khattak et al, $2013^{41}$ & Swat (KP) & 170 & $37(21.76 \%)$ & $10(5.88 \%)$ \\
\hline Din et al, $2014^{42}$ & Rawalpindi (Punjab) & 95 & 47 (49.47\%) & $3(3.15 \%)$ \\
\hline Nazir et al, $2014^{43}$ & Lahore (Punjab) & 200 & $82(41 \%)$ & NA \\
\hline Khan et al, $2015^{44}$ & Bannu (KP) & 180 & 14 (7.77\%) & NA \\
\hline Saeed et al, $2015^{45}$ & ICT & 262 & $146(55.72 \%)$ & $8(3.07 \%)$ \\
\hline Ali et al, $2016^{46}$ & Faisalabad (Punjab) & 379 & $123(32.45 \%)$ & NA \\
\hline Kiani et al, $2016^{47}$ & $\begin{array}{l}\text { ICT, Rawalpindi (Punjab) and Karachi } \\
\text { (Sindh) }\end{array}$ & 1,253 & $273(21.78 \%)$ & $38(3.03 \%)$ \\
\hline Khalil et al, $2016^{48}$ & Rawalpindi (Punjab) & 80 & $31(38.75 \%)$ & $4(5 \%)$ \\
\hline Sultan et al, $2016^{49}$ & Karachi (Sindh) & 100 & $27(27.0 \%)$ & $3(3.0 \%)$ \\
\hline Khan et al, $2017^{50}$ & Lahore (Punjab) & 470 & $216(45.95 \%)$ & $37(7.87 \%)$ \\
\hline Bari et al, $2017^{51}$ & Mardan (KP) & 44 & $19(43.18 \%)$ & NA \\
\hline Farooq et al, $2018^{52}$ & ICT & 1,440 & 295 (20.4\%) & $44(3.05 \%)$ \\
\hline Raza et al, $2018^{53}$ & Lahore (Punjab) & 200 & $53(26.50 \%)$ & NA \\
\hline Shah et al, $2019^{54}$ & Hazara (KP) & 324 & $18(5.55 \%)$ & $6(1.85 \%)$ \\
\hline Abid et al, $2019^{55}$ & Lahore (Punjab) & 95 & $6(6.31 \%)$ & $2(2.17 \%)$ \\
\hline Yasmeen et al, $2019^{56}$ & $\begin{array}{l}\text { Lahore, Multan (Punjab), Karachi } \\
\text { (Sindh) and Peshawar (KP) }\end{array}$ & 350 & 103 (29.42\%) & $26(7.42 \%)$ \\
\hline Al-Moshary et al, $2019^{57}$ & Peshawar (KP) & 430 & $102(23.72 \%)$ & $21(4.88 \%)$ \\
\hline
\end{tabular}

Abbreviations: HBV, hepatitis B virus; HCV, hepatitis C virus; ICT, Islamabad capital territory; KP, Khyber Pakhtunkhwa; NA, not available.

replacement" instead of the WHO recommended regular voluntary donations, ${ }^{59}$ the probability of acquiring the infection increases. The rampant use of poor quality RDTs ${ }^{60}$ for screening purposes intensifies the situation. Hence, unsafe blood transfusions remained an important driver of the hepatitis epidemic in the country.

The findings of this study showed that the maximum pooled prevalence of $\mathrm{HBV}$ and HCV among thalassemia patients was observed in Punjab Province (10.14 and 41.34\%, respectively). On the other hand, the least pooled prevalence for HBV was seen in Islamabad Capital Territory (3.05\%), while for HCV it was in Khyber Pakhtunkhwa Province (24.17\%). The transfusion system in general and the screening system in specific could explain, at least partially, such findings.

Countries like Iran, Cyprus, and Italy ${ }^{61-63}$ have a successful experience of eradicating thalassemia and it is vital that Pakistan should learn and follow a similar strategy. This strategy should then be adapted to local needs and requirements to formulate a national consensus for thalassemia prevention policy.

To the best of our understanding, this was the first systematic review to assess the pooled prevalence of HBV and 
HCV among thalassemia patients in Pakistan. It is pertinent to mention that the total sample size of 33 studies was less than $10 \%(n=8,554)$ of the total number of estimated thalassemic patients, that is, 100,000 .

Further studies or a national baseline survey are imperative to confirm the actual frequency of HBV and HCV in thalassemia patients across the country in various settings that in turn may lead to better management of the problem.

\section{Limitations}

More than $90 \%$ of the studies incorporated in this systematic review reported the prevalence on the basis of serological tests; hence, there is a likelihood of missing occult HBV and $\mathrm{HCV}$ infections. Regional biasness is present as studies were not conducted in some geographical areas.

\section{Conflict of Interest}

None.

\section{References}

1 Rund D, Rachmilewitz E. Beta-thalassemia. N Engl J Med 2005;353(11):1135-1146

2 Kuesap J, Chaijaroenkul W, Rungsihirunrat K, Pongjantharasatien K, Na-Bangchang K. Coexistence of malaria and thalassemia in malaria endemic areas of Thailand. Korean J Parasitol 2015;53(3):265-270

3 Flint J, Harding RM, Boyce AJ, Clegg JB. The population genetics of the haemoglobinopathies. Baillieres Clin Haematol 1998;11(1):1-51

4 Modell B, Darlison M. Global epidemiology of haemoglobin disorders and derived service indicators. Bull World Health Organ 2008;86(6):480-487

5 Taher AT, Weatherall DJ, Cappellini MD. Thalassaemia. Lancet 2018;391(10116): :155-167

6 Cappellini MD, Cohen A, Porter J, Taher A, Viprakasit V. Thalassemia International Federation: Guidelines for the clinical management of thalassemia. 3rd edition; 2014. Available at https://thalassaemia.org.cy/publications/tif-publications/ guidelines-for-the-management-of-transfusion-dependent-thalassaemia-3rd-edition-2014/. Accessed May 1, 2021

7 Borgna-Pignatti C, Rugolotto S, De Stefano P, et al. Survival and complications in patients with thalassemia major treated with transfusion and deferoxamine. Haematologica 2004;89(10):1187-1193

8 Waheed U, Arshad M, Saeed M, et al. Spectrum of alloimmunization among multitransfused beta-thalassemia major patients. Glob J Transfus Med 2019;4(1):39-44

9 Waheed U, Wazeer A, Qasim Z, Iqbal Z, Zaheer HA. Surveillance of adverse transfusion reactions in multitransfused thalassaemia patients in Mirpur, Azad Jammu and Kashmir, Pakistan. Pak Inst Med Sci 2016;12(1):27-30

10 Dumaidi K, Al-Jawabreh A, Samarah F, Rabayaa M. Prevalence of sero-molecular markers of hepatitis $C$ and $B$ viruses among patients with $\beta$-thalassemia major in Northern West Bank, Palestine. Can J Infect Dis Med Microbiol 2018;2018:1039423

11 Atwa ZT, Abdel Wahed WY. Transfusion transmitted infections in frequently transfused thalassemic children living in Fayoum Governorate, Egypt: current prevalence and risk factors. J Infect Public Health 2017;10(6):870-874

12 Raheemtoola RJ. Cooley's anaemia in Pakistani children. Medicus 1960;20:101

13 Khateeb B, Moatter T, Shaghil AM, Haroon S, Kakepoto GN. Genetic diversity of beta-thalassemia mutations in Pakistani population. J Pak Med Assoc 2000;50(9):293-296
14 Zaheer HA, Waheed U. Development of a national thalassemia policy in Pakistan. Glob J Transfus Med 2017;2(1):69-70

15 Khattak MF, Saleem M. Prevalence of heterozygous beta-thalassemia in northern areas of Pakistan. J Pak Med Assoc 1992;42(2):32-34

16 Zaheer HA, Waheed U, Abdella YE, Konings F. Thalassemia in Pakistan: a forward-looking solution to a serious health issue. Glob J Transfus Med 2020;5(1):108-110

17 Zaheer HA, Waheed U. Blood safety system reforms in Pakistan. Blood Transfus 2014;12(4):452-457

18 The Sindh Government Gazette. The Sindh Prevention and Control of Thalassemia Act, 2013, Act No. I of 2013. Provincial Assembly of Sindh. Available at: http://www.pas. gov.pk/uploads/acts/Sindh\%20Act\%20No.I\%20of\%202014.pdf. Accessed on May 1, 2021

19 The Balochistan Gazette. The Balochistan Prevention and Control of Thalassemia Bill, 2015, Act No. XIV of 2015. Balochistan Provincial Assembly Secretariat. Available at: http://pabalochistan.gov.pk/pab/pab/tables/alldocuments/ actdocx/2018-10-23\%2012:23:49act-14-2015.pdf. Accessed on May 1, 2021

20 Ahmed S. Genetic haemoglobin disorders in Pakistan. Nat J Health Sci 2017;2(3):95-99

21 Pakistan National Hepatitis Strategic Framework 2017-21; Ministry of National Health Services, Pakistan. Available at: http://www.phrc.org.pk/assets/pakistan-s-national-hepatitis-strategic-framework-09-01-2018.pdf. Accessed on May 1, 2021

22 Higgins JPT, Thomas J, Chandler J, et al. Cochrane Handbook for Systematic Reviews of Interventions. 2nd edition . Chichester, UK: John Wiley \& Sons; 2019 DOI:10.1002/9781119536604

23 Moher D, Liberati A, Tetzlaff J, Altman DG; PRISMA Group. Preferred reporting items for systematic reviews and meta-analyses: the PRISMA statement. PLoS Med 2009;6(7):e1000097

24 The Joanna Briggs Institute. Critical Appraisal Tools for Use in JBI Systematic Reviews Checklist for Prevalence Studies. The University of Adelaide, Adelaide, Australia. Available at: https://joannabriggs.org/research/critical-appraisal-tools. html. Accessed on May 1, 2021

25 Bhatti FA, Amin M, Saleem M. Prevalence of antibody to hepatitis $C$ virus in Pakistani thalassaemics by particle agglutination test utilizing C 200 and C 22-3 viral antigen coated particles. J Pak Med Assoc 1995;45(10):269-271

26 Abdul Mujeeb S, Shiekh MA, Khanani R, Jamal Q. Prevalence of hepatitis $C$ virus infection among beta-thalassaemia major patients. Trop Doct 1997;27(2):105

27 Shamsi T, Ahmed A, Taj Z, Vajid MA, Hassan F. Prevalence of hepatitis B, C and HIV virus infection among beta thalassaemia major patients. J Pak Med Assoc 1998;48(3):87

28 Akhtar S, Moatter T, Azam SI, Rahbar MH, Adil S. Prevalence and risk factors for intrafamilial transmission of hepatitis $C$ virus in Karachi, Pakistan. J Viral Hepat 2002;9(4):309-314

29 Mohammad J, Hussain M, Khan MA. Frequency of hepatitis B and hepatitis $C$ infection in Thalassemic children. Pak Pediatr J 2003;27(4):161-164

30 Younus M, Hassan K, Ikram N, Naseem L, Zaheer HA, Khan MF. Hepatitis $\mathrm{C}$ virus seropositivity in repeatedly transfused thalassemia major patients. Int J Pathol 2004;2(1):20-23

31 Burki MFK, Hassan M, Hussain H, Nisar YB, Krishan J. Prevalence of anti-hepatitis $C$ antibodies in multiply transfused beta thalassemia major patients. Ann Pak Inst Med Sci. 2005;1(3):150-153

32 Shah SMA, Khan MT, Ullah Z, Ashfaq NY. Prevalence of hepatitis $B$ and hepatitis $C$ virus infection in multitransfused thalassaemia major patients in North West Frontier Province. Pak J Med Sci 2005;21(3):281-284 
33 Hussain $\mathrm{H}$, Iqbal R, Khan MH, et al. Prevalence of hepatitis $\mathrm{C}$ in beta thalassaemia major. Gomal J Med Sci 2008;6(2):87-90

34 Iqbal MM, Hassan S, Aziz S. Frequency of hepatitis B and C in multi-transfused beta thalassemia major patients. Pak Armed Forces Med J 2010;60(2):285-288

35 Ain Qurat-ul, Ahmad L, Hassan M, Rana SM, Jabeen F. Prevalence of $\beta$-thalassemic patients associated with consanguinity and anti-HCV - antibody positivity-a cross sectional study. Pak J Zool 2011;43(1):29-36

36 Ali I, Siddique L, Rehman LU, et al. Prevalence of HCV among the high risk groups in Khyber Pakhtunkhwa. Virol J 2011;8:29610.1186/1743-422X-8-296

37 Riaz H, Riaz T, Ullah F, et al. Assessment of the seroprevalence of viral hepatitis B, viral hepatitis C and HIV in multitransfused thalassaemia major patients in Karachi, Pakistan. Trop Doct 2011;41(1):23-25

38 Rehman MU, Ullah B, Jan F, Chishti T. Correlation of hepatitis $C$ with multiple blood transfusions in children of thalassemia major. Pak J Med Health Sci 2011;5(2):323-326

39 Ansari SH, Shamsi TS, Khan MT, et al. Seropositivity of hepatitis C, hepatitis B and HIV in chronically transfused $\beta$-thalassaemia major patients. J Coll Physicians Surg Pak 2012;22(9):610-611

40 Iqbal A, Farrukh H, Aslam S, Iqbal T. Frequency of hepatitis $\mathrm{C}$ in B-thalassemia major patients. Rawal Med J 2013;38(4):328-331

41 Khattak IUD, Shah M, Ahmed I, Rehman A, Sajid M. Frequency of hepatitis $B$ and hepatitis $C$ in multitransfused beta thalassaemia major patients in district Swat. Journal of Saidu Medical College 2013;3(2):99-302

42 Din G, Malik S, Ali I, Ahmed S, Dasti JI. Prevalence of hepatitis $C$ virus infection among thalassemia patients: a perspective from a multi-ethnic population of Pakistan. Asian Pac J Trop Med 2014;7S1(Suppl 1) :S127-S133

43 Nazir S, Faraz A, Shahzad N, et al. Prevalence of HCV in $\beta$-thalassemia major patients visiting tertiary care hospitals in Lahore - Pakistan. Adv Life Sci 2014;1(4):197-201

44 Khan MS, Ahmed M, Khan RA. Mushtaq N, Wasim Ullah Shah M. Consanguinity ratio in b-thalassemia major patients in District Bannu. J Pak Med Assoc 2015;65(11):1161-1163

45 Saeed U, Waheed Y, Ashraf M, Waheed U, Anjum S, Afzal MS. Estimation of hepatitis B virus, hepatitis $C$ virus and different clinical parameters in thalassemic population of capital twin cities of Pakistan. Virology (Auckl) 2015;6:11-1610.4137/VRT. S31744

46 Ali MA, Arif M, Arif A, Fatima T. Viral hepatitis C in thalassaemia: determination of antibody HCV frequency in mutitransfused thalassaemia patients. APMC 2016;10(1):20-25

47 Kiani RA, Anwar M, Waheed U, Abbasi S, Zaheer HA. Epidemiology of transfusion transmitted infection among patients with $\beta$-thalassaemia major in Pakistan. J Blood Transfus 2016;8135649:5, doi: 10.1155/2016/8135649

48 Khalil S, Khan HS, Akhtar P. Status of hepatitis B and C in beta thalassemia major patients. J Islamabad Med Dent Coll 2016;5(2):71-73
49 Sultan S, Irfan SM, Siddiqui M,Zaidi SMH. Current trends of seroprevalence of transfusion transmitted infections in Pakistani $\beta$-thalassaemic patients. Malays J Pathol 2016;38(3):251-255

50 Khan MR, Anwar S, Faizan M, Nosheen S. The burden of transfusion related infections on thalassemia major children. Pak J Med Health Sci 2017;11(3):882-886

51 Bari F, Shah SF, Munir SS, et al. Hepatitis C virus diagnosis among multi-transfused beta thalassemia major patients. Gomal J Med Sci. 2017;15:128-132

52 Farooq A, Waheed U, Zaheer HA, Rauf A, Arshad A, Arshad M. Incidence of hepatitis $B$ and $C$ viruses in thalassaemia major patients. Pak J Zool 2018;50(3):1191-1194

53 Raza T, Ahmed S, Rafiq S, Shah A, Khalid U. Frequency of hepatitis $C$ virus infection in multitransfused patients of beta thalassemia major at a tertiary care hospital in Lahore. Pak Pediatr J 2018;42(2):106-110

54 Shah T, Hussain W, Ali N, et al. Frequency distribution and risk factors of hepatitis B virus and hepatitis $C$ virus infections among thalassemia patients: a regional study. Eur J Gastroenterol Hepatol 2019;31(2):248-252

55 Abid MZU, Ali SM, Hassnain S, Altaf Z, Khalid MU, Tariq S. Seroconversion of hepatitis $B$ and $C$ in paediatric patients with thalassemia major and its awareness among parents. Biomedica 2019;35(3):170-173

56 Yasmeen H, Hasnain S. Epidemiology and risk factors of transfusion transmitted infections in thalassemia major: a multicenter study in Pakistan. Hematol Transfus Cell Ther 2019;41(4):316-323

57 Al-Moshary M, Al-Mussaed E, Khan A. Prevalence of transfusion transmitted infections and the quality of life in $\beta$-thalassemia major patients. Cureus 2019;11(11):e612910.7759/ cureus.6129

58 Qureshi H, Bile KM, Jooma R, Alam SE, Afridi HUR. Prevalence of hepatitis B and C viral infections in Pakistan: findings of a national survey appealing for effective prevention and control measures. East Mediterr Health J 2010;16(Suppl):S15-S23

59 Waheed U, Wazeer A, Saba N, Qasim Z. Effectiveness of WhatsApp for blood donor mobilization campaigns during COVID-19 pandemic. ISBT Sci Ser. 2020;15(4):378-380

60 Waheed U, Abdella YE, Saba NE, et al. Evaluation of screening effectiveness of hepatitis B surface antigen and anti-HCV rapid test kits in Pakistan. J Lab Physicians 2019;11(4):369-372

61 Hashemieh M, Timori Naghadeh H, Tabrizi Namini M, Neamatzadeh H, Hadipour Dehshal M. The Iran Thalassemia Prevention Program: success or failure? Iran J Ped Hematol Oncol 2015;5(3):161-166

62 Kalokairinou EM. The experience of $\beta$-thalassaemia and its prevention in Cyprus. Med Law 2007;26(2):291-307

63 Cao A, Rosatelli MC, Galanello R. Control of beta-thalassaemia by carrier screening, genetic counselling and prenatal diagnosis: the Sardinian experience. Ciba Found Symp 1996;197:137-151, discussion 151-155 